\title{
ASSESSMENT OF NUTRITIONAL STATUS IN CHILDREN WITH SECONDARY MALNUTRITION VERSUS CHILDREN WITH ADEQUATE NUTRITIONAL STATUS
}

\author{
M. Oana, C. Mihaela, P. Anamaria \\ Pediatrics I, Medicine University Targu Mures, Târgu-Mures, Romania
}

Child malnutrition in developed countries is mainly due to secondary chronic diseases and it can be aggravated by prolonged hospitalization. Child malnutrition has severe consequences for growth, development and health.

Objectives and aim: Are to assess the nutritional status of children with cancer compared with children with other causes of malnutrition and with control group.

Material and method: A prospective study was performed on 106 children hospitalized in the Pediatric Clinic I Tg.-Mures, Romania, between November 1, 2010- february 2011, children who were divided into three groups: group 1, children with malnutrition of different causes: 25 cases $(23.58 \%)$, group 2, children with neoplastic diseases 33 cases $(31.13 \%)$ and control group 3, consisting of 48 children (45.28\%) with normal nutritional status.

Results and discussions: In study group 1 we observed a low weight $-3,22 \mathrm{SD}$, comparative with control group, $\{p=0.001\}$. We got statistically significant differences in terms of height $(p=0.0022), B M I(p=0.0001)$ and MUAC ( $\mathrm{p}=0.0001)$; all parameters beeing much lower in the group with malnutrition, less decreased in the group with oncological diseases compared with controls.

In addition, it was observed a good correlation, statistically significant between BMI and total serum proteins in children in group $1,(\mathrm{p}=0.05)$ and significant correlation to both as group 1 and group 2 between the MUAC and serum albumin $(\mathrm{p}=0,05)$.

In conclusion we found to be most affected nutrional status in children with malnutrition secondary to other causes than the cancer, BMI, MUAC and serum protein, respectively albumin characterize better nutritional status. 